\title{
ANTILIBERALISMO Y FASCISMO CATÓLICO. LAS DOS CARAS DEL PENSAMIENTO POLÍTICO DE MARIO GÓNGORA*
}

\author{
ANTI-LIBERALISM AND CATHOLIC FASCISM. THE TWO \\ FACES OF MARIO GÓNGORA'S POLITICAL THOUGHT
}

\section{VALENTINA VERBAL ${ }^{* *}$}

Resumen: En este trabajo se estudian dos componentes fundamentales del pensamiento político de Mario Góngora, que sus comentaristas han tendido a pasar por alto o al menos a minimizar: antiliberalismo y fascismo católico. Sostengo que, mientras el antiliberalismo representa la cara o dimensión reaccionaria del pensamiento de Góngora, el fascismo católico representa su cara o dimensión propositiva. Además, y complementariamente al objetivo indicado, este artículo busca constatar la presencia de estos componentes a lo largo de toda la vida intelectual de Góngora.

Palabras Clave: Mario Góngora, Ensayo histórico, pensamiento político, antiliberalismo, fascismo católico.

AbSTRACT: This work studies two fundamental components in Mario Góngora's political thought that his commentators have tended to overlook or at least minimize: anti-liberalism and Catholic fascism. The author maintains that while anti-liberalism represents the reactionary facet or dimension of Góngora's thought, Catholic fascism represents the propositional facet or political dimension of his thought. Furthermore, this article seeks to verify the presence of these components throughout Góngora's intellectual life.

Keywords: Mario Góngora, Historical Essay, Political thought, anti-liberalism, Catholic fascism.

Recibido: 15.05.20. Aceptado: 19.08.2021.

* Agradezco los generosos comentarios de Benjamín Ugalde y Felipe Schwember, así como las agudas sugerencias de los evaluadores de este artículo. Además, de manera muy especial, agradezco a la profesora Aurora Morcillo, una gran experta en el fascismo español, quien me motivó a estudiar a Mario Góngora desde esta perspectiva de análisis.

${ }^{*}$ Magíster en Historia (Beca Conicyt). Doctoranda en Historia Atlántica, en Florida International University, Miami, Estados Unidos (becaria Fulbright). Correo electrónico: vverb001@fiu.edu. Orcid: http://orcid.org//0000-0002-0650-1565 


\section{INTRODUCCIÓN}

Dese a que existe un consenso bastante extendido en que Mario Góngora del Campo (1915-1985) ha sido uno de los más importantes historiadores en Chile, este trabajo lo considerará como un pensador político, más que como un historiador. En este sentido, aunque él expresó planteamientos políticos durante toda su vida, no fue sino hasta la publicación, en 1981, de su Ensayo histórico sobre la noción del Estado en Chile en los siglos $X I X$ y XX que su figura adquirió una fuerte connotación política, al menos desde un punto de vista intelectual.

Después de su publicación, el Ensayo histórico de Góngora suscitó ricos debates sobre su interpretación de la vida republicana de Chile y, de manera particular, en torno a su postura frente a la dictadura militar (1973-1990), encabezada por Augusto Pinochet. Probablemente haya sido este segundo aspecto el más decisivo a la hora de posicionar a Góngora como un punto de referencia intelectual en términos políticos. No es casualidad, en este sentido, que luego de la publicación del referido Ensayo histórico, Góngora haya concedido varias entrevistas a influyentes medios de prensa en Chile. Por ejemplo, en una entrevista para El Mercurio -un periódico identificado con la derecha-, la periodista Raquel Correa (1984) le pregunta directamente a Góngora sobre su pensamiento político y, en particular, sobre su posición frente al régimen militar. Con respecto a lo primero, cuando Correa le pregunta si él es corporativista, Góngora afirma: "Ya no, déjeme explicarle" (p. D3). Y agrega:

Todo gobierno tiene que fundarse en un principio de legitimidad dentro del cual esté contenido el consentimiento popular. Monarquía, aristocracia y democracia, cuando son sentidos como legítimos, incluyen esa aceptación expresa o tácita, en distintas formas, según los países y las épocas. En América española, el dogma jurídico fundamental después de 1810, es la democracia y, por tanto, yo lo profeso. Pero lo esencial es que la mayoría no impida la libertad de las minorías y de los individuos excepcionales, que la democracia no sea tiránica, como la que en Atenas condenó a Sócrates. (Correa, 1984, p. D3)

Si el lector de esta cita no se encuentra tan informado sobre la obra historiográfica y política de Góngora, podría legítimamente pensar que, en 1984 (el año de esta entrevista), o incluso en 1981 (cuando publicó su Ensayo histórico), él era un demócrata estándar o incluso un demócrata liberal, como muchos otros pensadores lo fueron en el contexto de la Guerra Fría. 
Y pese a que en no pocas entrevistas (no solo en la de Correa) Góngora tiende a maquillar sus ideas políticas, lo cierto es que ellas sí están presentes en el conjunto de su obra, aunque de manera especial en su emblemático ensayo de 1981.

Sin embargo, y frente a la pregunta de Correa sobre el régimen de Pinochet, Góngora es mucho más directo y explícito. Cuando Correa (1984) le pregunta sobre la existencia de una dictadura en el país, Góngora responde:

En toda Hispanoamérica, el fenómeno de los gobiernos militares es algo de ordinaria ocurrencia debido a que los polos dominantes del poder en América española han sido, fundamentalmente, la aristocracia y el ejército, después de la ruptura de la monarquía hispánica. (p. D3)

Pero, pese a esta consideración un tanto ambigua, agrega que el problema que en ese momento el país experimentaba, no estaba radicado en la existencia de un régimen militar en sí mismo, sino fundamentalmente en su alianza "con los Chicago", refiriéndose a los llamados "Chicago boys", un grupo de economistas que habían cursado programas de posgrado en economía en la Universidad de Chicago, bajo la dirección de profesores como Arnold Harberger o Milton Friedman, entre varios otros. Según Góngora, esta influencia sobre el régimen militar habría provocado una suerte de decadencia cultural en Chile que, específicamente, habría estado representada por el abandono, por parte del Estado, de su rol de "mediador entre todos los intereses" (Correa, 1984, p. D3). Sin embargo, y como veremos más abajo, Góngora no cree en una función meramente arbitral del Estado, sino en un rol de creador de la identidad nacional.

Además, considerando el amplio debate que la figura intelectual de Góngora ha generado en Chile, no deja de llamar la atención que la gran mayoría de sus comentaristas refiera muy por encima sus ideas políticas de fondo. Lo anterior se conecta con el hecho de que su figura ha terminado adquiriendo un carácter transversal entre comentaristas de las más variadas tendencias políticas. Por ejemplo, en Geraldo y Vergara (2017), autores de distintas tendencias ideológicas, así como desde diferentes aproximaciones disciplinares, expresan -casi a coro- una gran condescendencia y simpatía por el pensamiento político de Góngora, aunque obviamente no por las mismas razones. Mientras algunos de tendencia conservadora parecen valorar el estatismo moral de Góngora, otros de tendencia socialista hacen lo propio con su antiliberalismo económico (Verbal, 2020).

Pero, por ejemplo, todos ellos apenas consideran el hecho de que, durante toda su vida, Góngora fue un decidido enemigo de la democracia re- 
presentativa, un sistema basado en el voto individual y en la preeminencia de los partidos políticos por encima de las corporaciones gremiales. Además, estos autores tienden a omitir el hecho de que Góngora no se opuso a la dictadura de Pinochet por atentar contra las libertades civiles y políticas, sino básicamente por instaurar un sistema económico liberal. Y aunque algunos autores mencionan ciertas conexiones de Góngora con el fascismo (Verbal, 2020), este termina siendo calurosamente aplaudido por supuestamente haberse "enfrentado" al régimen de Pinochet.

Dicho todo lo anterior, este trabajo argumenta que el pensamiento político de Góngora puede resumirse en dos ejes fundamentales, que la gran mayoría de sus comentaristas han tendido a pasar por alto o al menos a minimizar: antiliberalismo y fascismo católico. Mientras el antiliberalismo representa el aspecto reaccionario de su pensamiento político, el fascismo católico da cuenta de su mismo pensamiento, pero ahora en términos propositivos. Además, este trabajo muestra la presencia de estos elementos en distintos momentos en distintos momentos de la vida intelectual de Góngora.

Dicho lo anterior, valga la siguiente aclaración terminológica. Se ha preferido utilizar la expresión pensador político más que la de intelectual públi$c o$, ya que esta última categoría suele ser más amplia y, en general, hoy tiende a ser utilizada para referirse a personas que buscan influir en los medios de comunicación, incluso en las redes sociales. Por ejemplo, en calidad de analistas, columnistas, etcétera. En este sentido, el filósofo estadounidense Robert Nozick explica que los intelectuales públicos no son necesariamente "personas inteligentes o de cierto nivel de educación, sino (...) quienes en sus actividades se ocupan de las ideas expresadas en palabras, moldeando las corrientes de éstas que otros reciben" (Nozick, 2005, p. 236). Los intelectuales públicos, agrega Nozick, son simples, pero muy influyentes, "hacedores de palabras" (p. 236). Y Góngora no fue propiamente eso, sino más bien un historiador que, al mismo tiempo, buscó pensar e interpretar el país desde la mirada de sus ideas políticas.

Este artículo se ordenará del siguiente modo. La siguiente sección (2) estará orientada a explicar y fundamentar teóricamente las categorías principales utilizadas en este trabajo: antiliberalismo y fascismo católico. Luego (3), se abordará el antiliberalismo de Góngora como la cara reaccionaria de su pensamiento político. Posteriormente (4), se hará lo propio con el fascismo católico, la cara propositiva de ese mismo ideario. Finalmente (5), se cerrará el trabajo con una conclusión que apunta a sintetizar y reafirmar la tesis propuesta. 


\section{ANTILIBERALISMO Y FASCISMO CATÓLICO. UNA BREVE PERO NECESARIA DIGRESIÓN TEÓRICA}

Probablemente por su carácter negativo, la categoría antiliberalismo no ha sido demasiado estudiada en historia, filosofía política y, en general, en el ámbito de las humanidades y las ciencias sociales. Por ejemplo, para la palabra antiliberalism (sentido negativo), el portal JSTOR arroja solamente 744 resultados de búsqueda. En cambio, para liberalism (sentido positivo), el mismo portal muestra la impresionante cantidad de 194.001 resultados de búsqueda (este sencillo "experimento" fue hecho en el mes de abril del año 2020).

Por esta misma razón, resulta aconsejable explicar el significado de este concepto. Para ello, vale la pena seguir a un autor que lo ha tratado de manera monográfica, tanto a nivel abstracto como también a partir del estudio de algunos pensadores fundamentales. Se trata de Stephen Holmes (1996) $\mathrm{y}$ de su libro The Anatomy of Antiliberalism, publicado originalmente en 1993. Este trabajo, valga aclarar, se focaliza en el antiliberalismo de derechas más que en el de izquierdas, mucho más estudiado.

Para Holmes (1996), son varias las características o señales a partir de las cuales puede identificarse o detectarse el antiliberalismo que él estudia en su libro. Por razones de brevedad, veamos aquí solamente dos: a) el sentimiento de decadencia cultural o patologización del presente, y b) el mito del atomismo social o del individualismo egoísta. La primera característica o señal considera que el mundo actual se encuentra en una crisis profunda, que es necesario superar. Normalmente, el antiliberalismo considera que la cultura occidental se encuentra en decadencia. En este sentido, explica Holmes, los dardos de los antiliberales suelen dirigirse contra la modernidad y contra el liberalismo, considerado como el producto político de aquella. Dice Holmes (1996): "Los ataques contra la modernidad llegaron a ser reemplazados por ataques contra el liberalismo. La fraseología cambió, pero el patrón subyacente de hostilidad, menosprecio y reprensión siguió siendo el mismo" (p. xii). ${ }^{1}$

Una segunda característica del antiliberalismo se refiere a la idea de que el liberalismo produciría una atomización de la sociedad. Holmes ejemplifica este elemento en dos pensadores concretos: Alasdair MacIntyre y Robert Nisbet. MacIntyre afirma que el liberalismo desconocería que los in-

\footnotetext{
${ }^{1}$ Todas las traducciones del inglés han sido hechas por la autora de este artículo.
} 
dividuos se enfrentan al mundo en el contexto de diferentes comunidades, como la familia, la tribu, la ciudad y la nación. Y aunque no pueda decirse, aclara Holmes, que los comunitaristas (como MacIntyre) sean neofascistas, sí puede al menos constatarse que su base argumental es prácticamente la misma que la del fascismo; y que, de hecho, no se han preocupado demasiado por diferenciarse de esa ideología (1996, pp. xii-xxiv).

Por su parte, Nisbet (1962) señala que los fundadores del liberalismo, como John Locke, Adam Smith y Thomas Jefferson, creían en un "hombre abstracto, inherentemente autosuficiente, equipado simultáneamente con instintos y razón para construir su autonomía" (p. 225). Sin embargo, Holmes (1996) señala que el liberalismo clásico más bien "ataca las cadenas orgánicas de dependencia y subordinación, al mismo tiempo que busca socavar los clanes peligrosos y grupos sectarios" (p. 193). En otras palabras, el liberalismo tuvo su centro en el individualismo, no entendido como egoísmo, sino como la valoración del derecho de los individuos a perseguir fines propios, independientemente del grupo de nacimiento o de pertenencia. En otras palabras, se trata de la superación de la sociedad estamental o de capas.

Mientras la categoría antiliberalismo no ha sido muy estudiada en términos académicos, la de fascismo católico (o hispanoamericano) lo ha sido en mucha mayor medida. En general, los autores que han trabajado el fascismo desde una perspectiva global tienden a coincidir en que esta ideología política ha asumido históricamente diversas modalidades, no reduciéndose únicamente a las versiones más conocidas del fascismo italiano y del nazismo alemán. No por nada, al preguntarse qué es el fascismo en la historia, Finchelstein (2019) sostiene que el fascismo es un fenómeno trasnacional, es decir que no cabe solamente considerarlo en términos nacionales, sino también desde el punto de vista de las transferencias e intercambios más allá de las fronteras internas, especialmente europeas (p. 58).

Un segundo autor que asume una perspectiva amplia del fascismo es Stanley G. Payne (1980), quien detalla diversas experiencias fascistas más allá de Italia y Alemania, entre las que se encuentran los casos de España y Portugal. Para el caso español, explica los hitos principales de la evolución del fascismo en esa nación, siendo fundamentales los nombres de Ernesto Giménez Caballero, Ramiro Ledezma Ramos y José Antonio Primo de Rivera (Payne, 1980, pp. 145-147). Por ejemplo, al referir a las Juntas de Ofensiva Nacionalsindicalista, fundadas por Ledesma Ramos el 10 de octubre de 1931, recalca Payne (1980) el componente nacionalsindicalista de su ideario (p. 146). 
Además, en otro libro -dedicado especialmente a la Falange Española, fundada por José Antonio Primo de Rivera el 29 de octubre de 1933- explica Payne (1985) que, pese a que el fascismo español tiene antecedentes anteriores a la fecha de la fundación de la Falange, no fue sino con Primo de Rivera fue el fascismo hispanoamericano adquirió carta de ciudadanía en Occidente. Pese a haber coqueteado con el liberalismo en sus años universitarios, Primo de Rivera terminó profundamente decepcionado de esta tendencia ideológica, principalmente por asociarla a las componendas partidistas y, en particular, a la -para él- injusta oposición de la cual habría sido víctima la dictadura que encabezó su padre, Miguel Primo de Rivera, entre 1923 y 1930. Payne (1985) explica este punto de la siguiente manera:

José Antonio llegó a despreciar a la intelectualidad liberal por la cual se había sentido atraído cuando era estudiante. Cuanto más atacaban y ridiculizaban aquéllos a su padre, más aumentó su hostilidad hacia la democracia de la clase media liberal y las formas parlamentarias. (p. 48)

Concretamente, J.A. Primo de Rivera demostró su fuerte rechazo al liberalismo en varias publicaciones periódicas. En una de ellas, sostiene que "Para el liberalismo nada es absolutamente verdad ni mentira. La verdad es, en cada caso, lo que dice el mayor número de votos" (Torrente Ballester, 1940, p. 36). Para el fundador de la Falange, bajo un Estado liberal la sociedad no podría preservar un destino común, puesto que su propósito consistiría en garantizar la existencia de múltiples destinos.

Según Payne (1985), el fascismo puede asumir dos grandes combinaciones: nacionalismo y socialismo (nazismo) y nacionalismo y corporativismo (fascismo italiano y español) (p. 26). De acuerdo a Ludovico Incisa (1991), el corporativismo "es una doctrina que propugna la organización de la colectividad sobre la base de asociaciones representativas de los intereses y de las actividades profesionales (corporaciones)" (p. 372). Desde esta perspectiva, las corporaciones ( $\mathrm{y}$ no los individuos) son las llamadas a tener representación política en el Estado. Por lo mismo, esta visión plantea un fuerte rechazo al voto individual, a los partidos políticos y, en general, a las formas parlamentarias. Precisamente, la Falange englobó esta visión bajo la etiqueta de nacionalsindicalismo.

Ahora bien, para entender el concepto de fascismo católico, debemos dar un tercer paso. Ya hemos visto que el fascismo es un fenómeno trasnacional y que el fascismo hispanoamericano, representado emblemáticamente por el fascismo español, tiene su centro en el corporativismo nacionalsindicalista. Pero ¿cómo se expresa concretamente ese nacionalismo? ¿Cuál es la 
identidad nacional que se llama a defender? Aquí entra a jugar un papel relevante la categoría de fascismo católico. Un autor que ha trabajado esta categoría -que aquí recojo-, es Chris Bannister (2012). De acuerdo a este autor, lo que hizo J.A. Primo de Rivera fue hispanizar (o hacer católico) el fascismo italiano, mediante una síntesis entre ideas fascistas originarias -desarrolladas por Mussolini y Gentile- y algunas creencias del tradicionalismo católico español (p. 92).

Recuerda Bannister (2012) que, cuando la Falange española fue fundada en 1933, Primo de Rivera creía que España se encontraba en una crisis o en decadencia, por haber perdido su destino histórico (p. 95). Precisamente la recuperación de ese destino pasaba por combinar, ya no solo el nacionalismo con el corporativismo (nacionalsindicalismo), sino también hacer lo propio con el catolicismo (fascismo católico).

Aunque Payne (1980) no utiliza la expresión fascismo católico, sino más bien la de fascismo español, sí sostiene que el componente católico resulta fundamental en este tipo de fascismo: "El falangismo difería en tanto del fascismo italiano en su básica identidad católica (aunque anticlerical) (...)" (p. 149). Y agrega algo fundamental: "El concepto falangista de "hombre nuevo' incorporó así casi todas las cualidades del héroe católico tradicional, aunque fusionándolas con componentes del siglo XX” (p. 149).

\section{ANTILIBERALISMO. LA CARA REACCIONARIA DEL PENSAMIENTO POLÍTICO DE GÓNGORA}

Una excepción que confirma la regla en relación a la categorización de nuestro pensador como antiliberal, puede constatarse en un reciente libro de Diego González Cañete (2018), que estudia las figuras intelectuales de Eduardo Frei Montalva, Jaime Eyzaguirre y Mario Góngora. ${ }^{2}$ A pesar de la alta calidad de este trabajo, González Cañete se refiere a la influencia fascista en Góngora exclusivamente para el período de entreguerras, en particular para la década de 1930. En un anterior trabajo, González Cañete

\footnotetext{
${ }^{2}$ Eduardo Frei Montalva fue presidente de Chile, como líder del Partido Demócrata Cristiano (PDC), entre 1964 y 1970. Para la historia del PDC, hasta el gobierno de Frei Montalva, puede revisarse el trabajo de Grayson (1968). Para la figura misma de Frei Montalva, puede verse Gazmuri (2000). Jaime Eyzaguirre fue, durante el siglo XX, uno de los más importantes historiadores hispanistas en Chile; no en términos de ser un especialista en historia de España, sino más bien por el hecho de haber sido un apasionado defensor de la cultura española y de su influencia sobre Chile y Latinoamérica. Para su vida y figura intelectual, puede revisarse Vial Correa, Góngora Escobedo y de la Taille (2002).
} 
(2017) centra su atención en la noción de estatismo más bien que en otras categorías más complejas, como la de fascismo católico. Pero, como ya se ha dicho, este artículo buscará constatar la presencia del antiliberalismo y fascismo católico a lo largo de toda la vida de Góngora.

A pesar de la limitación temporal referida en el párrafo precedente, el libro de González Cañete constituye una excelente puerta de entrada al pensamiento político de Góngora en su juventud. El autor presenta muy bien -y con bastante detalle- el contexto político en el cual Góngora construyó su visión de sociedad. Por ejemplo, da cuenta del hecho de que, siendo un joven estudiante de leyes en la Universidad Católica de Chile, en 1932 comenzó a participar en algunas organizaciones sociales, como la Asociación Nacional de Estudiantes Católicos (ANEC). Ligado a esto, el autor también constata que, dos años más tarde, nuestro pensador estaba meditando acerca de una posible entrada a la vida política, específicamente a las filas del Partido Conservador. Según González Cañete (2018), mientras hacía eso, Góngora expresaba en su diario de vida un firme "antiliberalismo' y un 'monarquismo y autoritarismo pronunciados" (p. 63). Efectivamente, en una entrada de su Diario, fechada el 22 de noviembre de 1934, Góngora (2013) confiesa de manera abierta que "el estudio de la historia medieval me puso perfectamente reaccionario, integralista, antiliberal, anheloso de buscar una posición radicalmente romántica" (p. 73).

Además, el antiliberalismo de Góngora no aparece solo expresado en su Diario, sino también en un importante discurso, de fecha 10 de octubre de 1937, y que lleva por título "Bases espirituales del orden nuevo". En este discurso, que fue realizado en el Teatro Miraflores, con ocasión de una convención de la Juventud del Partido Conservador, a la que se había sumado tiempo antes, Góngora expresa de manera bastante clara su antiliberalismo, tanto en el plano político (contrario a la democracia) como económico (contrario al capitalismo).

En dicho discurso (Tierra, 1937, pp. 33-40), Góngora critica tanto la democracia como el capitalismo. Sobre la primera, afirma que dicho sistema político se sostiene sobre la base del sufragio universal, que convierte al pueblo en una masa inorgánica en favor de los dueños del dinero. Con respecto al segundo, no dudaba en señalar que necesariamente la "defensa de la dignidad humana pasaba por la instauración de una economía colectivista o comunitaria.

Entrando de manera más precisa en la caracterización de Holmes (1966) sobre el concepto de antiliberalismo, puede sostenerse que tanto el sentimiento de decadencia cultural como el mito del atomismo social están pre- 
sentes de manera muy marcada en el pensamiento de Góngora. Un ejemplo de esto puede verse en una entrada de su Diario, fechada el 17 de diciembre de 1934. Aquí Góngora comenta sobre una de sus muchas lecturas: "La gloria de don Ramiro, obra llena de carácter, interesantísima, en que describe perfectamente esa España del Siglo de Oro con su rey, su Iglesia, sus altivos caballeros. ¡Cuán distinto, cuán anticristiano y cuán antipopular es el orden de hoy día!" (Góngora, 2013, p. 77)³. Esta cita es interesante porque da cuenta de manera inequívoca de la presencia del elemento tradicionalista en el pensamiento político de Góngora.

Su admiración política por la Edad Media puede también apreciarse en un artículo posterior al Ensayo histórico de Góngora (1981). En este otro trabajo, Góngora (1985) señala que el trasfondo de la libertad en Chile e Hispanoamérica viene de la teoría política medieval (p. 11). Para sostener esta idea, remite a las reglas del debido proceso, como la garantía de que nadie puede ser juzgado sin un juicio previo. Al parecer, se refiere a la Carta Magna de 1215. Esto es interesante porque las garantías que este documento consagra fueron establecidas en favor de los nobles, y no del conjunto de la población. Esta idea puede fácilmente colegirse de la lectura de sus disposiciones, que contienen derechos diferenciados en favor de los condes, barones y obispos del Reino. O, a lo sumo, de los "hombres libres" o "ciudadanos de Londres".

Asimismo, el elemento decadentista de Góngora puede también apreciarse en una entrevista de 1934. Aquí dice Góngora: "El desorden político es una derivación de la anarquía que se ha apoderado de la vida individual y social desde que ella perdió su centro religioso" (González Cañete, 2018, p. 159). Además, agrega que el liberalismo es el gran culpable de este desorden, ya que las absurdas libertades liberales son la negación misma de la dignidad humana, pues ellas se basan en el desconocimiento del carácter espiritual y social del hombre" (González Cañete, 2018, p. 159). Como se aprecia, Góngora rechaza el concepto de libertad individual y solo la defiende de manera corporativa.

En su Ensayo histórico, Góngora (1981) se lamenta de que el régimen de Pinochet, al instaurar un modelo basado en libertades económicas, refleje un nuevo contexto de decadencia cultural. Dice Góngora (1981): "La idea cardinal del Chile republicano es, históricamente considerado, que es el Estado el que ha ido configurando y afirmando la nacionalidad chilena a

${ }^{3}$ La gloria de don Ramiro es una novela de Enrique Larreta, publicada en 1908. 
través de los siglos XIX y XX" (p. 134). Y luego agrega: "Ahora, en cambio [bajo el régimen militar], se expande la tendencia a la privatización y la convicción de que la libertad económica es la base de la libertad política y finalmente de toda libertad (...)" (1981, p. 134).

Curiosamente, este mismo rechazo a la libertad económica estuvo también presente en 1966, varios años antes del Ensayo histórico, y en la época en que gobernaba Eduardo Frei Montalva (1964-1970), bajo la así llamada "revolución en libertad" o "vía no capitalista de desarrollo". En este ensayo, Góngora (1966) argumenta que el capitalismo es contrario a la identidad nacional, la cual legítimamente debe ser configurada por el Estado: "No se trata solamente de crear un grupo que persiga el lucro a través de la empresa (1987b, p. 177), sino que también, agrega, es necesario formar "una convicción de la legitimidad de su existencia" y "una creencia en la eticidad y valor de ese género de vida" (1987b, p. 177).

En otras palabras, Góngora cree que, aunque la ética del capitalismo pueda ser exitosa en países protestantes, con gran dificultad podría serlo en países de raigambre católica y española. Para Góngora, además, constituye una responsabilidad fundamental del Estado la protección de los valores católicos y la garantía de su proyección hacia el futuro. Por lo mismo, para él, el liberalismo económico instaurado por Pinochet no hacía otra cosa que traicionar tanto la identidad histórica de Chile como el deber del Estado de conservarla y proyectarla en el tiempo.

Dicho de una manera simple, para Góngora el liberalismo siempre conduce a la decadencia cultural en términos morales y al atomismo social, debido a que, bajo sus principios, las personas solo perseguirían intereses propios, no colectivos o corporativos. Además, no necesariamente relacionados con la identidad nacional que el Estado, por una suerte de mandato histórico, estaría obligado a proteger.

En otro ensayo, sobre romanticismo y tradicionalismo, Góngora (1987a) expresa su visión en torno a la relación entre los individuos y la comunidad establecida por el Estado:

Entonces, la comunidad del Estado contiene al individuo, pero el individuo a su vez, en cierta manera, contiene a la comunidad. De modo que la polaridad [entre individuos y comunidad] impide que este concepto de totalidad estatal de que he hecho mención sea el puro fenómeno de la sujeción radical de un individuo, que éste sea en el fondo un átomo. En esta concepción no hay atomismo, sino polaridad entre lo comunitario, llamémoslo así, y lo individual. (p. 62) 
Sin embargo, en la línea de su visión política, el liberalismo (entendido sencillamente como democracia representativa y libre mercado) consideraría únicamente el "polo de los individuos", desenraizados de la comunidad, puesto que sus vidas se basarían fundamentalmente en intereses egoístas, no mediados por el Estado, el gran creador de la nación, y de una nación esencialmente católica, como veremos en la siguiente sección.

\section{FASCISMO CATÓLICO. LA CARA PROPOSITIVA DEL PENSAMIENTO POLÍTICO DE GÓNGORA}

A primera vista, podría parecer exagerado calificar a Góngora como fascista, especialmente si se aplica el término a secas, sin el adjetivo católico o hispanoamericano. Sin embargo, resulta innegable que su pensamiento político posee fuertes conexiones con ese tipo de fascismo. Como veremos, dicho ideario constituye una síntesis bastante marcada entre nacionalismo, corporativismo y catolicismo, triada fundamental en el fascismo católico.

$\mathrm{Si}$, como se dijo en la introducción, todavía se ha profundizado poco en el pensamiento político de Góngora, en mayor medida incluso puede sostenerse que la mayoría de los autores que lo han estudiado tienden a pasar por alto o a minimizar la cara fascista de su ideario. Por ejemplo, Patricia Arancibia Clavel (1985) dice que "es un error afirmar que el corporativismo sustentado por Góngora y la Juventud conservadora [de la cual él formaba parte] tuvo su origen en el fascismo" (p. 147), y luego agrega:

Como el propio Góngora se encargó de desmentir en su oportunidad a Sergio Villalobos, la generación católica de los años 30, incluyendo aquí al grupo encabezado por Jaime Eyzaguirre y la revista Estudios, propició las tesis corporativistas basándose especialmente en las corrientes socialcristianas de los siglos XIX y XX y, más particularmente, en la encíclica Quadragessimo Anno. (1985, p. 147)

Sin embargo, sobre este comentario cabría decir tres cosas. En primer lugar, el corporativismo que menciona Arancibia Clavel sí tuvo, en el contexto de Occidente -incluyendo a Chile- fuertes lazos con un tipo especial de fascismo, el fascismo católico o hispanoamericano. Pareciera que Arancibia Clavel identifica la categoría fascismo únicamente con el fascismo italiano y con el nazismo alemán, sin adoptar la visión más amplia o global recogida por una gran cantidad de expertos en el fascismo, como los referidos en la segunda sección de este artículo. 
En segundo término, no parece verosímil afirmar que la encíclica Quadragesimmo Anno (1931) propone un sistema corporativista. Allí se consagran más bien los principios de subsidiariedad y asociatividad. Mediante el primero, señala Pío XI, "la suprema autoridad del Estado permita resolver a las asociaciones inferiores aquellos asuntos y cuidados de menor importancia” (párr. 80). Y a través del segundo, agrega el mismo pontífice,

así como los habitantes de un municipio suelen crear asociaciones con fines diversos con la más amplia libertad de inscribirse en ellas o no, así también los que profesan un mismo oficio pueden igualmente constituir unos con otros asociaciones libres con fines en algún modo relacionados con el ejercicio de su profesión. ( $\left.n^{\circ} 87\right)$

Más atrás, señala el Papa que

no se puede quitar a los individuos y dar a la comunidad lo que ellos pueden realizar con su propio esfuerzo e industria, así tampoco es justo, constituyendo un grave perjuicio y perturbación del recto orden, quitar a las comunidades menores e inferiores lo que ellas pueden hacer y proporcionar y dárselo a una sociedad mayor y más elevada, ya que toda acción de la sociedad, por su propia fuerza y naturaleza, debe prestar ayuda a los miembros del cuerpo social, pero no destruirlos y absorberlos. $\left(n^{\circ} 79\right)$

En ninguna parte de la encíclica se propone un sistema político de corte corporativista, sino a lo sumo la creación de asociaciones mayores a partir de asociaciones menores previamente existentes. Asimismo, en ningún caso se propugna que esas asociaciones puedan ser creadas coercitivamente por el Estado: "Las asociaciones libres que ya existen y disfrutan de saludables beneficios dispónganse a preparar el camino a esas asociaciones $\mathrm{u}$ 'órdenes' más amplios, de que hablamos, y a llevarlas a cabo decididamente conforme a la doctrina social cristiana" $\left(\mathrm{n}^{\circ} 87\right)$.

Tercero, el uso de una categoría o etiqueta no depende, al menos prima facie, de la circunstancia de que la persona estudiada se identifique o no con ella, sino de la utilidad metodológica que al estudioso le provee. En este sentido, si en este trabajo se conecta el pensamiento de Góngora con el fascismo de la Falange española, ello no se hace por el hecho de que nuestro pensador se haya definido -expresa o tácitamente- como cercano a esta tendencia, sino porque esa conexión ilumina el conjunto de su pensamiento. 
Aclarado el punto anterior, puede resultar útil señalar que el rechazo de Góngora a la democracia representativa o liberal es coincidente y sincrónico con el expresado por J. A. Primo de Rivera en España.

Al expresar ese rechazo, Góngora afirma su abierta adhesión al corporativismo. Desde una perspectiva filosófica, el corporativismo tiene su origen en una visión holística y organicista de la sociedad, que justamente se encuentra muy presente en el ideario de Góngora. De acuerdo a Karl Popper (2019), el holismo sostiene que el "grupo social es más que la mera suma total de sus miembros, y también es más que la mera suma de las relaciones meramente personales que existan en cualquier momento entre cualquiera de sus miembros" (p. 36). Por su parte, el organicismo es "la teoría que interpreta a los grupos sociales por medio de una analogía con los organismos vivos" (Popper, 2019, p. 38).

El holismo de Góngora se expresa, además, en el hecho de que él tiende a identificar el Estado con la sociedad. Citando a Edmund Burke, Góngora (1981) define el Estado como el contrato "entre los que están vivos, los que han muerto y los que nacerán" (p. 5). Sin embargo, y a pesar del hecho de que Arturo Fontaine Talavera (1982, p. 22) le hace ver que Burke se refiere a la sociedad y no al Estado, Góngora (2011) le responde que esa distinción no pertenecía a la época de Burke, que es más propia del siglo XIX, teniendo a Hegel como uno de sus principales artífices. Luego, en la misma respuesta, indica que su visión del Estado es holística, porque el "Estado es una idea de totalidad, en el sentido de un Ranke, o de los románticos, o del idealismo, que es en el fondo la idea tradicional de Estado, que viene desde Grecia, de las polis, de Platón y Aristóteles" (2011, p. 356) ${ }^{4}$.

Además, esta visión de sociedad puede también encontrarse treinta años antes de su Ensayo histórico, momento en que parece sentir una profunda admiración por el carácter corporativo del mundo medieval, en parte todavía vigente en Hispanoamérica durante el período de dominación española. Concretamente, en su libro El Estado en el Derecho Indiano, Góngora (1951) afirma que entre el siglo XIII y el siglo XV, Europa poseyó "formas estamentales del Estado" (p. 24) compuestas no solamente por "ligas juramentadas de señores, hidalgos, ciudades en defensa de sus privilegios" ( $\mathrm{p}$. 24), sino también por "instituciones permanentes, que constituyen propia-

\footnotetext{
${ }^{4}$ Valga aclarar que esta respuesta de Góngora a Fontaine Talavera aconteció en 1982, siendo publicada en la revista Economía y Sociedad n³, que correspondió al número siguiente en el que Fontaine publicó su comentario inicial. Sin embargo, en este trabajo se ha recogido el documento de la edición del Ensayo histórico de Editorial Universitaria, que contiene un interesante apéndice con diversas reacciones a dicho libro, incluyendo la respuesta de Góngora a Fontaine que da lugar a esta nota.
} 
mente estamentos cuando reciben, no solamente el privilegio de la jurisdicción autónoma (la 'justicia por los pares'), sino, además, la representación ante el rey como miembros del Reino" (p. 24).

Es importante notar que, aunque estas citas dan cuenta de una descripción más que de un juicio de valor, parece estar acompañada de una suerte de admiración moral por la Edad Media, que también puede apreciarse en muchos otros lugares de su obra, como algunos vistos más arriba. Pero, además, y esto parece ser más decisivo todavía, en Góngora suele apreciarse un fuerte rechazo hacia una idea de sociedad basada en los derechos individuales, y en un orden político orientado a protegerlos (constitucionalismo). De hecho, en su ensayo sobre romanticismo y tradicionalismo Góngora (1987) señala que: "[Para el romanticismo] El hombre mismo es comunidad y a la vez el Estado respeta al hombre como ser vivo y superior" (p. 62). En cambio, para Góngora (1987): “[El romanticismo] Admira a la Iglesia medieval como universalista y, a la vez, en polaridad con el universalismo, las nacionalidades, lo singular, la Nación, la provincia, la aldea, el individuo" (p. 63). Para él, aunque una sociedad ordenada deba reconocer la existencia de los individuos, ellos deben subordinarse a las comunidades.

Dicho lo anterior, puede resultar interesante considerar que esta visión -holística y organicista- de sociedad está también presente en su Ensayo histórico. Mientras la Declaración de Principios del régimen militar, orientada a justificar el golpe de Estado del año anterior, habría contenido -para Góngora-una "concepción orgánica del Estado" (1981, p. 134), "la revolución desde arriba" del neoliberalismo se habría convertido derechamente en una "tendencia antiestatal" (1981, p. 136). Luego ejemplifica este punto al criticar la consagración del principio de asociación en contra del "principio corporativo", según el cual las asociaciones profesionales tenían una función tutelar sobre el ejercicio de las profesiones de manera coercitiva (1981, p. 135). Toda su crítica, valga insistir, se inserta en su lamento por el abandono, de parte del Estado, de la función de crear y organizar en todo aspecto a la nación. Una nación entendida de un modo orgánico o corporativo, que debería negar los principios de subsidiariedad y asociatividad, consagrados -valga recordar- en la encíclica Quadragesimmo Anno (1931).

Ahora bien, habiendo ya ahondado en el corporativismo de Góngora, cabe decir algunas palabras sobre su nacionalcatolicismo. De manera muy similar al caso de Juan Egaña en el siglo XIX, Góngora piensa que si el Estado tiene naturalmente la función de crear la nación, ello no puede hacerlo ex nihilo, sino desde una identidad previa al mismo Estado, al menos al Estado republicano. Desde este punto de vista, la "creación" que el Estado 
realiza no es -no puede ser- completamente original, sino que se basa en un punto de partida que le precede. $Y$ a la luz de diversas fuentes, ese punto de partida es el catolicismo.

A pesar de que, algunas veces, Góngora no es tan explícito en su referencia al componente católico de la creación estatal, no resulta muy difícil inferirlo, en buena medida por el hecho de que Occidente estaría viviendo una crisis espiritual como consecuencia del materialismo que el liberalismo introduciría. En su discurso "Bases espirituales del orden nuevo", Góngora señala varias cosas interesantes. Primero, que el orden imperante, que llama a superar, omite la dimensión espiritual de los seres humanos. Segundo, que bajo el contexto del sistema capitalista, los burgueses católicos exploten a los pobres conforme a la idea de que la pobreza es una llamada evangélica (Tierra, 1937, pp. 33-40).

Por lo demás, precisamente por simpatizar con el fascismo español, más que meramente adherir a la doctrina social católica, es que la Falange chilena, fundada en 1936, se basó de un modo sustantivo -y no meramente estético- en la Falange española, y aunque sea cierto que Góngora no usó frecuentemente la palabra fascismo para referirse a su pensamiento, no deja de ser interesante que, en 1980, reconoce haber transitado por esa tendencia ideológica:

Pertenezco, salvadas todas las proporciones, a toda una generación europea que, desde 1900 a 1940 fue todo (comunista, fascista, tradicionalista, falangista marxista, etc.), antes que partidario de la realidad y de la palabra democracia. Y ahora, a los 65 años, [yo] soy uno de los vencidos (intelectualmente) de la II Guerra. (González Cañete, 2018, p. 223)

Por último, y como ya vimos para el Ensayo histórico, la nación que el Estado debería crear se aleja del protestantismo, precisamente por la conexión que Góngora hace entre esa rama del cristianismo y la mentalidad capitalista o empresarial, que él estima ajena a la cultura hispanoamericana. Recordemos que, en relación al régimen de Pinochet, Góngora da cuenta de un sentimiento -personal e íntimo- de crisis radical. No por el hecho del quiebre democrático de 1973, o de la dictadura que le sucedió, sino por la instauración de un sistema económico de libre mercado. Para Góngora, este sistema conduciría a que la sociedad pierda un horizonte moral de sentido, que debería ser creado por el Estado. Dice Góngora (1981): "Los ideales tradicionalistas y nacionalistas de la primera hora de la Declaración de Principios de 1974 [que apuntó a justificar el golpe de Estado de 1973], han quedado relegados al olvido ante el materialismo económico ambiente, 
por lo demás común a todo el mundo de masas" (p. 136). Para él, la crisis de la modernidad no es otra que la crisis a la que se está sometiendo la cultura occidental cristiana de base católica.

\section{CONCLUSIONES}

El presente artículo ha buscado relevar la figura de Mario Góngora como pensador político más que como historiador, aunque -como se ha vistoambos aspectos no pueden desligarse del todo. $\mathrm{Y}$ lo ha hecho a través del análisis de dos ejes fundamentales, que la gran mayoría de sus comentaristas ha tendido a pasar por alto o a minimizar: antiliberalismo y fascismo católico.

Representando la cara o dimensión reaccionaria de su pensamiento político, el antiliberalismo que lo caracteriza se ve reflejado en un sentimiento de decadencia cultural y moral que acompañó a Góngora durante toda su vida: en su juventud como estudiante universitario, en sus años de desarrollo como historiador, y también en su Ensayo histórico, publicado en 1981. Góngora siempre estuvo convencido de que las sociedades abiertas (democracia representativa y libre mercado) tienden al atomismo social, a provocar que las comunidades dejen de cumplir sus funciones naturales y, sobre todo, a que el Estado abandone su rol esencial de crear la nación desde una perspectiva católica.

Asimismo, y como cara propositiva de su pensamiento político, las ideas de Góngora dan cuenta de fuertes lazos con el fascismo católico, especialmente basados en una concepción holística y organicista de sociedad, a partir de la cual se debería apuntar a la construcción de un sistema de representación política de carácter corporativo. Este elemento también se encuentra presente en Góngora a lo largo de toda su vida. Sin embargo, no deja de llamar la atención que, a pesar de que algunas veces se alude a las conexiones de Góngora con el fascismo (Karmy, 2017; García de la Huerta, 2017) no se haya profundizado hasta hoy mayormente en ello, y menos todavía que esa alusión no se haya hecho de una manera crítica. Pareciera que el antiliberalismo integral de Góngora ha hecho que, por distintas razones, su figura intelectual termine adquiriendo un carácter "ecuménico", uniendo a intelectuales conservadores y socialistas de distintas vertientes.

Así como J. A. Primo de Rivera en España, Góngora es un ejemplo de que la categoría fascismo es mucho más amplia que el fascismo italiano y el nazismo alemán. En el fascismo católico o hispanoamericano confluye una 
doble combinación, que está muy presente en Góngora. Mientras, por una parte, puede reconocerse una alianza entre nacionalismo y corporativismo (dimensión política), por otra, puede hacerse lo propio entre fascismo y catolicismo (dimensión espiritual). De este modo, siguiendo a Góngora, la misión fundamental del Estado es la de crear la nación, ella debería llevarse a cabo a través de un proceso de fascistización tanto del corporativismo como del catolicismo.

Por último, podría agregarse que tampoco se ha problematizado en demasía su interpretación historiográfica según la cual "el Estado crea la nación". Al menos, esto no se ha hecho con suficiente profundidad. Recordemos que, de acuerdo a la interpretación de Góngora, el Estado habría creado la nación a partir de la guerra. Dice Góngora (1981): "La imagen fundamental y primera que de Chile se tiene es que constituye, dentro del Imperio Español en las Indias, una frontera de guerra, 'una tierra de guerra" (p. 7). Pero este elemento, para Góngora, habría sido también esencial en el proceso de construcción estatal durante el siglo XIX (1981, p. 9).

Dicho lo anterior, si se considera esta interpretación de Góngora como parte de su pensamiento político, podrían desprenderse algunas consecuencias problemáticas en el contexto de una sociedad abierta. Una de ellas guarda relación con el hecho de que, siguiendo a Jorge Larraín (2001), esta tesis podría también estar presente en varios otros autores que defienden una versión militar-racial de identidad chilena. Dice Larraín (2001) que la "versión militar-racial de la identidad chilena es oposicional por excelencia, en el sentido de que mucho más claramente que otras versiones requiere de un 'otro' al que hay que vencer o derrotar (p. 157). Ciertamente, visiones como estas han resultado siempre muy compatibles con el nacionalismo de corte corporativista y católico, al que Góngora fue muy cercano hasta sus últimos días de vida.

\section{REFERENCIAS}

Arancibia Clavel, P. (1985). Mario Góngora en busca de sí mismo. 1915-1946. Santiago: Fundación Mario Góngora.

Bannister, C. (2012). José Antonio Primo de Rivera: Catholic Fascism. En A. Quiroga y M. Á. del Arco. Right-Wing Spain in the Civil War Era. Soldiers of God and Apostles of the Fatherland, 1914-45 (pp. 91-116). New York: Continuum International Publishing Group.

Correa, R. (1984, 9 de diciembre). Mario Góngora. Las lecciones de la historia. El Mercurio, p. D3. 
Fontaine Talavera, A. (1982). Un libro inquietante. Economía y Sociedad, segunda época, 2, 22.

García de la Huerta, M. (1987). Nación-Estado y legitimidad en Chile. Reflexiones sobre un libro de Mario Góngora. Opciones, 57, 155-167.

Gazmuri, C. (2000). Eduardo Frei Montalva y su época, con la colaboración de Patricia Arancibia y Álvaro Góngora. (2 vols.). Santiago: Aguilar Chilena de Ediciones.

Geraldo, G., y Vergara, J. C. (eds.) (2017). Mario Góngora: el diálogo continúa. Once reflexiones sobre su obra. Santiago: Historia Chilena.

Góngora, M. (1937). Un orden nuevo. Tierra, 4, 33-40.

Góngora, M. (1981). Ensayo histórico sobre la noción del Estado en Chile en los siglos XIX y XX. Santiago: La Ciudad.

Góngora, M. (1985). Libertad política y concepto económico de gobierno en Chile hacia 1915-1935. Historia, 20, 11-46.

Góngora, M. (1987a). Romanticismo y tradicionalismo. Civilización de masas y esperanza, $y$ otros ensayos (pp. 57-68). Santiago: Vivaria.

Góngora, M. (1987b). Materialismo capitalista. El actual ídolo del foro. Civilización de masas y esperanza, y otros ensayos (pp. 175-182). Santiago: Vivaria.

Góngora, M. (2013). Diario. Edición crítica de Leonidas Morales. Santiago: Editorial Universitaria; Ediciones UC.

González Cañete, D. (2017). ¿Estatismo como nostalgia? Mario Góngora y la génesis de una tesis polémica. En G. Geraldo y J. C. Vergara (eds.). Mario Góngora: el diálogo continúa. Once reflexiones sobre su obra (pp. 113-144). Santiago: Historia Chilena.

González Cañete, D. (2018). Una revolución del espíritu. Política y esperanza en Frei, Eyzaguirre y Góngora en los años de entreguerras. Santiago: Centro de Estudios Bicentenario.

Grayson, G. (1968). El Partido Demócrata Cristiano Chileno. Buenos Aires y Santiago: Francisco de Aguirre.

Holmes, S. (1996). Anatomy of Antiliberalism. Cambridge: Harvard University Press.

Incisa, L. (1991). Corporativismo. En N. Bobbio, N. Matteucci y G. Pasquino (directores). Diccionario de política (pp. 372-377). Madrid: Alianza.

Karmy, R. (2017). Teología de la historia. La historiografía de Mario Góngora como una apocalíptica. En G. Geraldo y J. C. Vergara (eds.). Mario Góngora: el diálogo continúa. Once reflexiones sobre su obra (pp. 99-111). Santiago: Historia Chilena.

Larraín, J. (2001). La identidad chilena. Santiago: Lom.

Nisbet, R. A. (1962). Community and Power. New York: Oxford University Press.

Nozick, R. (2005). ¿Por qué los intelectuales se oponen al liberalismo? En A. Roemer (comp.). Felicidad. Un enfoque de derecho y economía (pp. 235245). México D.F.: UNAM; THEMIS. 
Payne, S. G. (1980). Fascism. Comparison and Definition. Madison: Wisconsin University Press.

Payne, S. G. (1985). Falange. Historia del fascismo español. Madrid: Sarpe.

Pío XI (1931). Carta encíclica Quadragesimmo Anno. Documentos. disponible en: https://www.vatican.va/content/pius-xi/es/encyclicals/documents/ hf_p-xi_enc_19310515_quadragesimo-anno.html

Popper, K. R. (2019). La miseria del historicismo. Madrid: Alianza.

Torrente Ballester, G. (1940). José Antonio Primo de Rivera (Antología). Barcelona: Ediciones Fe.

Verbal, V. (2020). Mario Góngora como pensador político. Un debate inconcluso. Historia y Geografía, 42, 45-68.

Vial Correa, G., Góngora Escobedo, Á. y de la Taille, A. (2002). Jaime Eyzaguirre en su tiempo. Santiago: Universidad Finis Terrae; Zig-Zag. 